\title{
THE PRESENTATION OF CHILDREN WITH AMBLYOPIA
}

\author{
G. WOODRUFF, F. HISCOX, J. R. THOMPSON and L. K. SMITH \\ Leicester
}

\begin{abstract}
SUMMARY
This study reports the presentation of 961 children who underwent amblyopia treatment at seven orthoptic centres in the United Kingdom. We confirmed previous authors' findings of a small but significant increased incidence of left-sided compared with right-sided amblyopia overall. For pure anisometropic amblyopia this difference was very marked and a possible pathophysiological mechanism is proposed. The mean age of presentation for anismetropic, strabismic and mixed amblyopia was 5.6, 3.3 and 4.4 years, respectively. Neither sex nor race affected the age of presentation. Despite their older age, children with pure anisometropic amblyopia had the best initial visual acuity, with $25 \%$ of anisometropes having an initial visual acuity of less than $6 / 18$ compared with $39 \%$ of strabismics and $50 \%$ of mixed amblyopes. The ages and initial acuities of the strabismic patients in this series are at least as favourable as those of patients reported from outside the UK. There were variations in the age and proportion of patients presenting with anisometropic amplyopia at the different centres, suggesting a failure in the referral of anisometropic amblyopia of importance in interpreting epidemiological studies.
\end{abstract}

The selection of patients and their clinical presentation are major factors responsible for the variable results of amblyopia treatment reported in the literature, with success rates ranging from $30 \%$ to over $90 \% .^{1-4}$ There is very little information about the presentation of children with amblyopia in the United Kingdom so that the relevance to British practice of the different results of treatment claimed in the literature is not clear. In addition, previous epidemiological studies based on clinic data have relied upon data from a single centre. We report on the presentation of a cohort of 961 children started on treatment for amblyopia at seven English centres. The outcome of this treatment is reported separately. ${ }^{5}$

\section{PATIENTS AND METHODS}

A research orthoptist and research assistant visited each of

Correspondence to: Geoffrey Woodruff, FRCOphth, Department of Ophthalmology, University of Leicester, Clinical Sciences Building, Leicester Royal Infirmary, PO Box 65, Leicester LE2 7LX, UK. seven English orthoptic centres which had agreed to participate in an audit of amblyopia treatment. The age at presentation, initial visual acuity and sex were recorded for every child who had had a first appointment in the orthoptic department in 1983, who had not had any previous treatment, and who was prescribed occlusion treatment for anisometropic, strabismic or mixed amblyopia at any time either at the first appointment or subsequently. Anisometropia was defined as a difference of 1 dioptre or more of either sphere or cylinder between the two eyes, and strabismus was defined as manifest strabismus on cover testing. The same research orthoptist determined the diagnosis from the information in the orthoptic records in the seven different centres. Children with an Asian surname or forename were classified as of Asian origin. ${ }^{6}$ Categorical data were analysed using the chi-squared $\left(\chi^{2}\right)$ test. Proportions were analysed using the Normal approximation to the Binomial distribution. Continuous data were analysed with regression analysis using $\mathrm{SAS}^{7}$.

\section{RESULTS}

Overall, 535 children had strabismic amblyopia (55\%), 164 had pure anisometropic amblyopia (17\%) and $262 \mathrm{had}$ mixed anisometropic and strabismic amblyopia (27\%) (Table I). There was a wide range in the proportion of patients with each type of amblyopia at the different centres $\left(\chi^{2}=21.1, p=0.05\right)$, with only $7 \%$ of the patients presenting with anisometropic amblyopia at centre B compared with $24 \%$ at centre C (Table I).

Left anisometropic amblyopia was more common (105 cases) than right anisometropic amblyopia (59 cases). For pure anisometropia this was so at each centre studied and was highly significant $(p=0.0003)$. For mixed anisometropic and strabismic amblyopia there was a less marked but still significant preponderance of left amblyopia (115 right, 147 left; $p=0.048$ ), while for pure strabismic amblyopia there was no significant difference (252 right, 283 left; $p=0.18$ ).

The mean age of first attending the orthoptic department for strabismic amblyopia was 3.3 years. Mixed strabismic and anisometropic amblyopia presented over 1 year later at 4.4 years. Pure anisometropes presented latest

Eye (1994) 8, 623-626 C 1994 Royal College of Ophthalmologists 
Table I. Number of patients with each type of amblyopia at seven centres

\begin{tabular}{llccrr}
\hline & & \multicolumn{3}{c}{ No. of children with each type of amblyopia } \\
\cline { 3 - 6 } Centre & Type of hospital & Strabismic & Anisometropic & Mixed & Total \\
\hline A & District eye hospital & 88 & 23 & 35 & 146 \\
B & Teaching hospital & 36 & 4 & 16 & 56 \\
C & University eye hospital & 57 & 31 & 33 & 131 \\
D & Children's teaching hospital & 77 & 20 & 11 & 128 \\
E & District general hospital & 23 & 10 & 68 & 44 \\
F & Teaching hospital & 113 & 49 & 58 & 210 \\
G & Teaching hospital & 141 & 164 & 262 & 246 \\
Total & & 535 & & & 961 \\
\hline
\end{tabular}

at 5.6 years (Table II). There was no significant difference in the age of presentation for children with strabismus (pure strabismic or mixed amblyopia) at the different centres (linear regression, $p=0.14$ and $p=0.13$ respectively). For pure anisometropic amblyopia the age of presentation was very significantly associated with the centre attended $(p=0.0001)$, with patients presenting to centres $E$ and $G 2$ years or more later than to centres $A$ and $C$. The mean age of presentation of patients with an Asian forename or surname was 4.7 years compared with 4.0 years in the non-Asians, but this was not significantly different after adjusting for centre and type of amblyopia (linear regression, $p=0.87$ ). There was no significant difference in the age of presentation of girls (4.0 years) compared with boys ( 4.0 years), even after adjusting for centre and type of amblyopia (linear regression, $p=0.91$ ).

In $80 \%$ of patients a measure of visual acuity was made before commencing treatment. The method used to determine visual acuity before commencing treatment varied according to age (Fig. 1). Except in two centres where Catford drum or mounted ball testing was used, the visual acuity of children in the 0-2 age group was not measured. The level of visual acuity prior to starting treatment recorded by Snellen or matching system is given in Fig. 2 . Overall, of children tested using one of these methods, $38 \%$ had a visual acuity (VA) less than $6 / 18$ and $62 \%$ had $6 / 18$ or better. The mean visual acuity $\exp [(\Sigma \log \mathrm{VA}) / n]$ was $6 / 20.3(n=341)$ for strabismic, 6/16.6 $(n=162)$ for pure anisometropic and 6/25.8 $(n=208)$ for mixed amblyopia. The range of visual acuities and the numbers of patients in each group were not large enough for differences between centres to be discernible.

\section{DISCUSSION}

A preponderance of left anisometropic amblyopia has not been widely recognised. However, review of the literature shows that Massie, ${ }^{8}$ Cole, ${ }^{9}$ Burian ${ }^{10}$ and Lippmann ${ }^{11}$ each found a slight overall preponderance of left amblyopia but did not analyse the contribution of different types of amblyopia to this observation. A consistent error in diagnosis due to a preference to test the acuity of the right eye first or due to a preference for refracting children from the right side rather than the left, could conceivably explain these results. However, we believe, in view of the previous literature, that our finding of an increased incidence of anisometropic amblyopia affecting the left eye is likely to be of pathophysiological significance. Right-handedness and right eye dominance are both more common than left dominance. ${ }^{12}$ Fabian ${ }^{13}$ termed the progressive reduction in the range of refractive errors in children emmetropisation. It is not clear how this process is controlled but it appears to be a vision-dependent phenomenon. ${ }^{14.15}$ We postulate that when random variations in refraction occur in infancy, the vision of the more dominant eye may be more effective at driving emmetropisation, thus making significant refractive errors and anisometropic amblyopia less common in dominant eyes.

Shaw et al..$^{16}$ noted an association between age of presentation and female sex and Asian origin. We found no evidence of this in our study. Pre-school vision screening has been introduced in an effort to promote an earlier approach to children with amblyopia. Children seen in the three centres $(A, C, G)$ which received referrals from preschool vision screening programmes were not significantly younger than children seen at other centres. However, we did not have sufficient data about the route of referral of individual patients or sufficient details of local screening programmes for any firm conclusions to be drawn about the effect of pre-school vision screening.

Table II. Age of presentation to seven orthoptic centres of patients with each type of amblyopia

\begin{tabular}{|c|c|c|c|c|c|}
\hline \multirow[b]{2}{*}{ Centre } & \multirow[b]{2}{*}{$n$} & \multicolumn{4}{|c|}{ Age of presentation $(\mathrm{yr})$} \\
\hline & & Anisometropic & Strabismic & Mixed & Total \\
\hline A & 146 & 4.8 & 2.9 & 4.4 & 3.6 \\
\hline B & 56 & 5.5 & 3.0 & 3.6 & 3.4 \\
\hline $\mathrm{C}$ & 131 & 4.8 & 3.7 & 5.1 & 4.4 \\
\hline D & 128 & 5.4 & 3.1 & 4.6 & 3.8 \\
\hline $\mathrm{E}$ & 44 & 7.1 & 3.4 & 3.7 & 4.3 \\
\hline $\mathrm{F}$ & 210 & 5.0 & 3.6 & 4.1 & 3.9 \\
\hline G & 246 & 6.7 & 3.3 & 4.4 & 4.2 \\
\hline Total & 961 & 5.6 & 3.3 & 4.4 & 4.0 \\
\hline
\end{tabular}




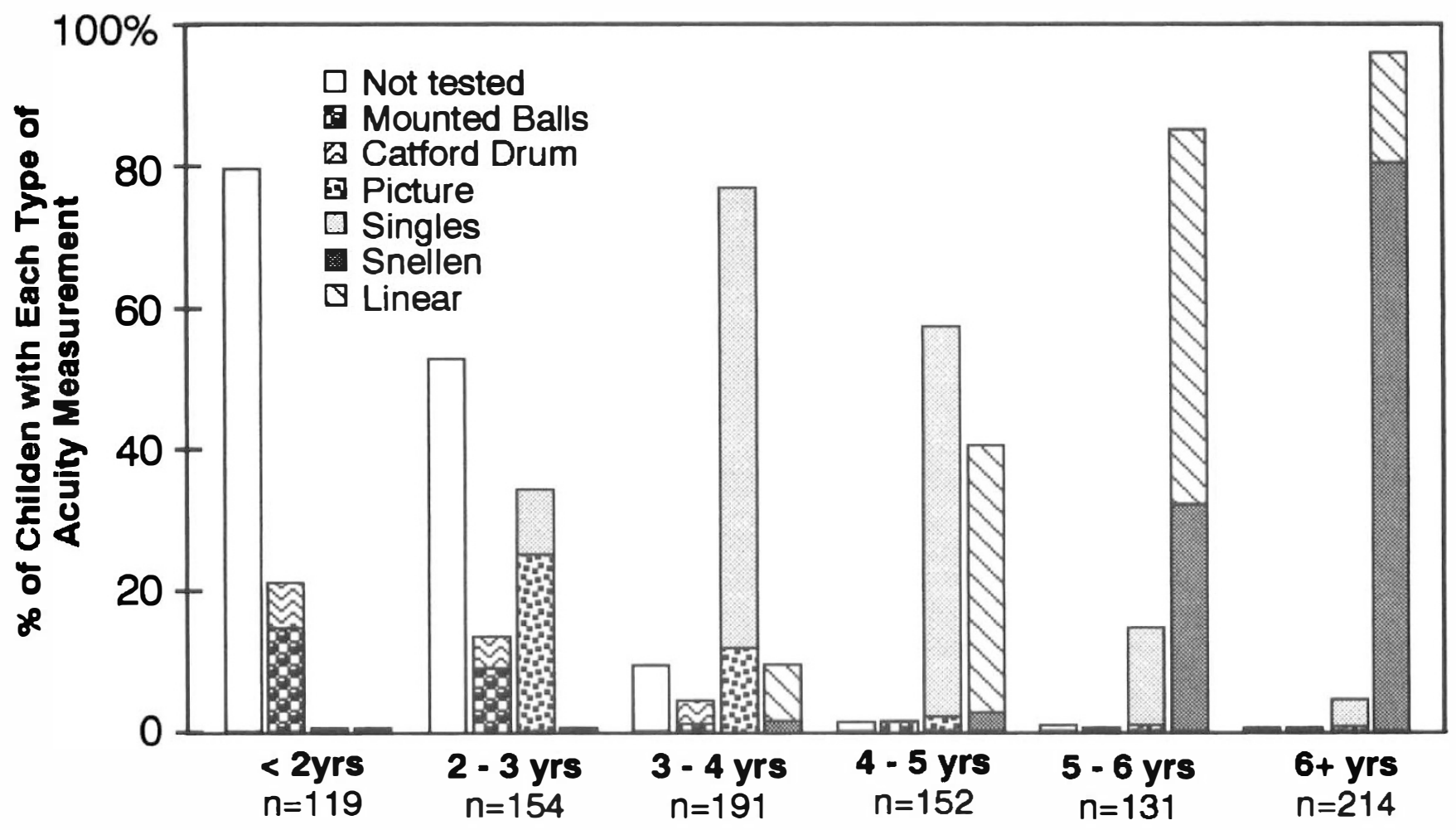

Age in Years

Fig. 1. Method of measuring the visual acuity of amblyopic patients presenting at different ages.

Sixty-two per cent of our patients had a visual acuity equal to or better than 6/18. While the Sheridan Gardiner method of testing may underestimate the degree of amblyopia in some patients it is clear that only a minority of children starting treatment in our centres had severe amblyopia. Lithander and Sjörstrand ${ }^{17}$ reported an overall age of children starting amblyopia treatment of 52 months - similar to our patients. However, only $27 \%$ of their patients had an acuity of $6 / 18$ or better before starting treatment. Fulton and Mayer ${ }^{18}$ reported a median age at first clinic visit of approximately 50 months in their patients with strabismic amblyopia compared with a mean age of 38 months in our series. The mean initial visual acuity ratio of their patients was approximately 0.34 , suggesting a higher proportion of patients with an acuity of less than 6/18 than at any of our centres. Because of the relative consistency of our findings for strabismic amblyopia at the different centres, it is possible that the presentation of strabismic amblyopia follows a similar pattern in other centres in the UK. In contrast, because of the differences in age of presentation of the anisometropic patients at our different centres, our findings for anisometropic

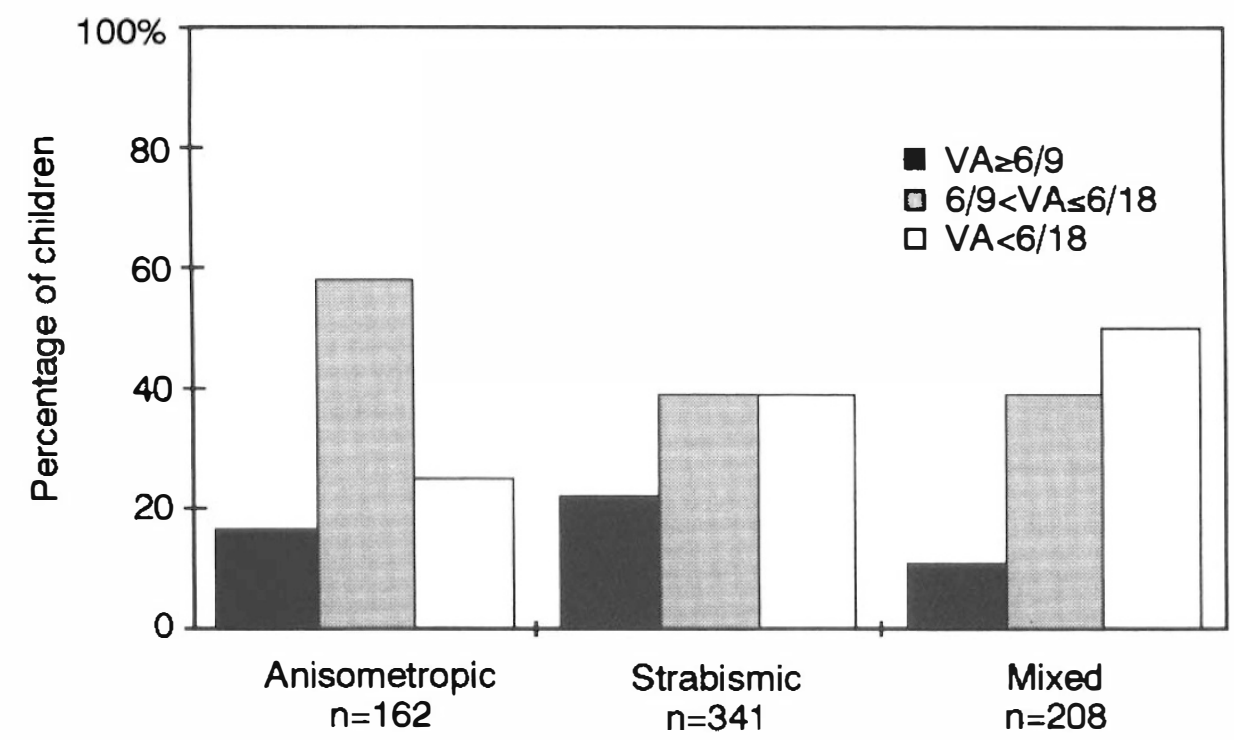

Fig. 2. Percentage of children with different levels of visual acuity recorded by Snellen or matching methods. 
amblyopia may be a poor guide to the presentation of this kind of amblyopia at other UK centres.

Epidemiological estimates of the relative proportions of non-strabismic and strabismic amblyopia vary, with values based on screening of adult populations (such as military enlistees) giving higher proportions of non-strabismic amblyopia ${ }^{19,20}$ than estimates based on the presentation of children to eye clinics. ${ }^{3}$ The lower proportion of anisometropes in studies based on clinical data has been attributed to the greater sensitivity of clinical studies for the diagnosis of microtropia. ${ }^{21}$ Our data suggest that this is not the explanation: first the incidence of non-strabismic amblyopia in our series remains low at $23 \%$ even if all the cases of microstrabismus are reclassified as non-strabismic. Secondly, the centre with significantly more anisometropia than other centres did not have a reduced propensity to diagnose microtropia. On the contrary, microtropia was noted in the orthoptic records more often at this centre ( 14 of 42 cases of mixed amblyopia) than at the other centres. Hardman Lea and Haworth ${ }^{22}$ have provided evidence from older children that undetected anisometropic amblyopia is common in the community whereas undetected strabismic amblyopia that remains undetected throughout childhood is rare (presumably because it is more obvious to parents). The variation in the proportion of amblyopes at different centres, combined with the variation in the age of presentation of anisometropic amblyopia, suggests to us a failure in the referral of anisometropic amblyopia that may be important in interpreting epidemiological studies.

We thank Jackie Nolan, Liz Newcombe, Rowena McNamara, Susan Viney, Jenny Elmer-Monaghan, Sheelagh Baker and the staff of the Orthoptic Clinics at Birmingham Children's Hospital, Bristol Eye Hospital, Leeds General Infirmary, Leicester Royal Infirmary, Queen's Medical Centre, Nottingham, Sunderland Eye Infirmary and Worthing Hospital. We gratefully acknowledge the financial support of the British Council for the Prevention of Blindness, The Iris Fund for Prevention of Blindness, The British Orthoptic Society and the Anne Allerton Fund.

Key words: Age, Amblyopia, Anisometropia, Epidemiology, Presentation.

\section{REFERENCES}

1. Hiscox F, Strong N, Thompson JR, Minshull C, Woodruff G. Occlusion for amblyopia: a comprehensive survey of outcome. Eye 1992;6:300-4.

2. Neumann E, Freidman Z, Abel-Peleg B. Prevention of strabismic amblyopia of early onset with special reference to the optimal age for screening. J Pediatr Ophthalmol Strabismus 1987;24:106-10.

3. Flynn JT, Cassady JC. Current trends in amblyopia therapy. Ophthalmology 1978;85:428-50.
4. Scott WE, Dickey CF. Stability of visual acuity in amblyopic patients after visual maturity. Arch Clin Exp Ophthalmol 1988;226:154-7.

5. Woodruff G, Hiscox F, Thompson JR, Smith LK. Factors affecting the outcome of children treated for amblyopia. Eye 1994;8:627-31.

6. Nicoll A, Bassett K, Ulijaszek SJ. What's in a name? Accuracy of using surnames and forenames in ascribing Asian ethnic identity in English populations. J Epidemiol Community Health 1986;40:364-8.

7. SAS Institute Inc. SAS user's guide: statistics, version 5. Cary, NC: SAS Institute, 1985.

8. Massie H. Fixing eye occlusion: survey of approximately 1000 case histories of patients who received occlusion of the fixing eye. Trans Ophthalmol Soc Australia 1965;24:39-46.

9. Cole RBW. The problem of unilateral amblyopia: a preliminary study of 10000 national health patients. BMJ 1959;1: 202-6.

10. Burian HM. Handedness, eyedness and refractive error in relation to strabismic amblyopia. Wiss Z Univ Leipzig Math Naturwiss R 1969;18:236.

11. Lippmann O. Die Entartungzeichen und die Überwertigkeit einer Körperhälfte in ihrer Bedeutung für das Sehen. Klin Monatsbl Augenheilkd 1934;92:370.

12. Hebben N, Benjamin D, Milberg WP. The relationship among handedness, sighting dominance and acuity dominance in elementary school children. Cortex 1981;17: 441-6.

13 Fabian G. Augenarzliche Reihenuntersuchung von 1200 Kindern im 2 Lebensjahr. Acta Ophthalmol (Copenh) 1966; 44:473-9.

14. Raviola E, Wiesel T. The mechanism of lid-suture myopia. Acta Ophthalmol (Copenh) 1988;185:91-2.

15. Rabin J, Van Sluyters RC, Malach R. Emmetropization: a vision-dependent phenomenon. Invest Ophthalmol Vis Sci 1981;20:561-4.

16. Shaw DE, Fielder AR, Minshull C, Rosenthal AR. Amblyopia: factors influencing age of presentation. Lancet 1988;2:207-9.

17. Lithander J, Sjörstrand J. Anisometropic and strabismic amblyopia in the age group 2 years and above: a prospective study of the results of treatment. Br J Ophthalmol 1991;75: 111-6.

18. Fulton AB, Mayer DL. Esotropic children with amblyopia: effects of patching on acuity. Graefes Arch Clin Exp Ophthalmol 1988;226:309-12.

19. Helveston EM. The incidence of amblyopia ex anopsia in young adult males in Minnesota in 1962-63. Am J Ophthalmol 1965;60:75-7.

20. Downing AH. Ocular defects in sixty thousand selectees. Arch Ophthalmol 1945;33:137-43.

21. Ciuffreda KJ, Levi DM, Selenow A. Amblyopia: basic and clinical aspects. New York: Butterworth Heinemann, 1990: 21-3.

22. Hardman Lea SJ, Haworth SM. An assessment of the present study for visual screening of school children in Nottingham. Br Orthopt J 1989;46:20-5. 